\title{
SEISMIC RESPONSE OF CIRCUIT BREAKERS
}

\author{
P.Surya Teja ${ }^{1}$, Sandeep Kumar. D.S ${ }^{2}$, Chethan Kumar.B ${ }^{3}$, Chethan.K ${ }^{4}$ \\ ${ }^{1}$ Post graduate Student, Department of Civil Engineering, P.E.S College of Engineering, Mandya, India \\ ${ }^{2}$ Assistant Professor, Department of Civil Engineering, P.E.S College of Engineering, Mandya, India \\ ${ }^{3}$ Assistant Professor, Department of Civil Engineering, Vijaya Vittala Inst of Technology, Bangalore, India \\ ${ }^{4}$ Assistant Professor, Department of Civil Engineering, UVCE, Bangalore, India
}

\begin{abstract}
The performance of substation equipment during an earthquake depends on their configuration, strength of construction, ductility and dynamic properties. Substation equipment's are lightly damped structures having one or more natural modes within the frequency band of ground excitation. The satisfactory operation of substation during and after an earthquake depends on the survival, without malfunction, of many diverse type of equipment. Porcelain components are identified as most vulnerable parts against earthquake vibrations than any other components of the substation. In this present work, substation equipment i.e., circuit breaker is used for analytical procedure. Electrical equipment is mounted on support structure. Support structure and porcelain insulator amplify the ground acceleration at the base of porcelain components. Dynamic characteristics of substation equipment are considered by carrying out finite element analysis. In the present work, maximum response spectral accelerations \& displacements of supporting structures, equipment and for both equipment placed on support structures are evaluated with respect to the zone factors. Furthermore, dynamic amplification factor (DAF) of substation support structures and along with its electrical equipment are obtained and effect of different parameters (e.g. support mass, height and stiffness) are discussed along with the recommendations available in International standards.
\end{abstract}

Keywords: Substation equipment, Porcelain Components, Circuit Breaker, Ground motion amplification, Dynamic Amplification Factor.

\section{INTRODUCTION}

Electric substation is an important part of electric power systems. The electric power industry cascades at three levels, in the chain between power generation and power supply. Occurrence of even an elementary fault in substation equipment may disrupt power supply, cause considerable damage to the power systems etc. Besides direct losses, collateral losses could be humongous besides loss of precious human life. The experience of past earthquakes shows that, although damages of the Electrical network installation are very extensive in length and area, they are infrequent. But the significance of these installations makes their protection and stability more important. Moreover, failure in electrical power system develops unacceptable gaps in economic interrelated issues.

In this paper functioning behavior of porcelain components used in circuit breaker with a supporting structure under damped condition have been studied. Results have been obtained using finite element analysis.

Finite element model of $36 \mathrm{kV}$ circuit breaker with damping condition is developed using SAP2000 software package. Ground amplification is obtained at the base of the porcelain components. The details of finite element model analysis have clearly brought out in this paper.

\subsection{Overview of Work Done in this Field:}

Sabelli et al., (2003) [3] worked on ground motion amplification and dynamic characteristics of concentrically braced steel frames as earthquake ground motion controls the performance of the structure. Based on the results he had improved design procedures and code provisions. Discussions were presented regarding the mechanical properties of buckling-restrained braced frames and special concentric braced frames. Buckling restrained frames became effective to overcome many potential problems associated with special concentric and ordinary moment resistant frames.

Mircea et al., (2010) [2] considered 220kV circuit breaker for combined analysis as a combination of EMA tests (Experimentally Modal Analysis using impact hammer tests) and direct vibratory tests (sine sweep tests) on the seismic platform in identifying seismic capability assessment. Theoretical analysis also can be made as an extension to EMA. Modal analysis parameters and frequency response functions are determined. Both the methods are comparable. The method combined analysis is proposed as strong method accepted by manufacturers and customers of high voltage equipment.

\section{SUPPORT STRUCTURE}

Substation Porcelain equipment is mounted on steel frames to maintain electrical clearances. These structures have a very significant effect on the motion that the supported 
equipment experience during an earthquake. The acceleration that the equipment experiences on a structure can be several times more severe than the ground acceleration. During qualification, it is generally desirable to have the equipment mounted or modelled in the identical manner, as it would be in its in-service configuration.

When the equipment is mounted on a support or a variety of supports and the parameters of the support(s) are not known, the qualification will be acceptable if the equipment is mounted or modelled without the support and the qualification is conducted at 2.5 times the requirements stipulated in the relevant standards. In the analysis, the support structure should be such that the supports do not amplify the loads at the base of the equipment greater than 2.25 times the base accelerations and the support(s) shall meet all requirements of recommended standards (IEEE Std., 693-2005).

The supporting structure is fabricated with mild steel angles. Height of steel support truss is $1785 \mathrm{~mm}$. The vertical members are fabricated using angle section $65 \mathrm{~mm} \times 65 \mathrm{~mm}$ $\mathrm{x} 6 \mathrm{~mm}$ and the horizontal and cross bracings using $65 \mathrm{~mm} \mathrm{x}$ $65 \mathrm{~mm} \times 6 \mathrm{~mm}$. The bracing members are connected to the vertical main members using mild steel bolts of $16 \mathrm{~mm}$ diameter. Modulus of elasticity and density of mild steel is taken as $200 \mathrm{GPa}$ and $7800 \mathrm{~kg} / \mathrm{m} 3$.

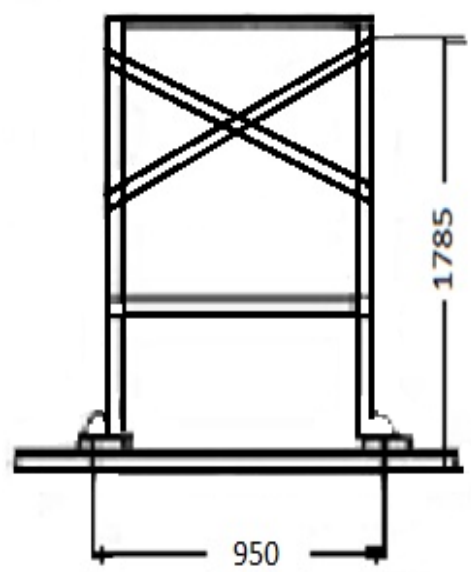

Fig -1: Support structure of 36kV Circuit Breaker

\subsection{Circuit Breaker}

Electrical circuit breaker is a switching device which can be operated both manually and automatically for controlling and protection of any electrical power system. As the modern power system deals with huge currents, the spacial attention should be given during designing of circuit breaker to safe interruption of arc produced during the opening/closing operation of circuit breaker.

According to their arc quenching (rapid cooling) media the circuit breaker can be divided as:

1) Air circuit breaker (ACB)

2) Oil circuit breaker (OCB)

3) Vacuum circuit breaker (VCB)

4) SF6 circuit breaker
Here, considered $36 \mathrm{kV}$ circuit breaker is a vacuum circuit breaker which is commonly used in substations. Vacuum circuit breakers are used mostly for low and medium voltages. Vacuum interrupters are developed for up to $36 \mathrm{kV}$ and can be connected in series for higher voltages. The interrupting chambers are made of porcelain and sealed. They cannot be open for maintenance, but life is expected to be about 20 years, provided that the vacuum is maintained. Service life of the VCB is much longer than other types of circuit breakers. There is no chance of fire hazard as oil circuit breaker. It is much environment friendly than SF6 circuit breaker.

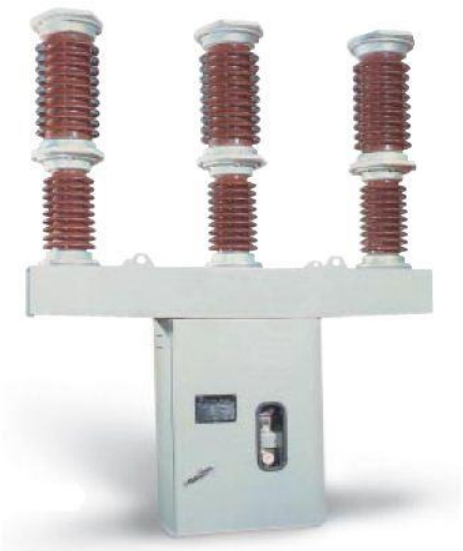

Fig -2: 36kV Circuit Breaker

\section{SEISMIC QUALIFICATION OF SUBSTATION EQUIPMENT}

The $36 \mathrm{kV}$ circuit breaker with steel supporting structure considered in this study was also a typical model as per the specification of Power utility. This equipment was an outdoor vacuum circuit breaker. Fault current is controlled by vacuum inside the porcelain insulators. Vacuum acts as medium to extinguish the arc generated in between the contacts while opening the circuit during the fault current. Switching mechanism, on and off switches are connected inside the porcelain insulators. These switches were controlled by the motor fixed inside the control cubicle.

\subsection{Finite Element Analysis}

Seismic qualification of the $36 \mathrm{kV}$ Circuit breaker by analysis was carried out using Finite element analysis software SAP2000. Few assumptions were made in modelling the equipment. Only structural elements were modelled. The mass of the electrical instruments like relays and switches were appropriately lumped at respective nodes and their stiffness characteristics are ignored in order to reduce the complexity in modelling. Porcelain elements are modelled with solid elements and members of supporting steel frame were modelled with truss elements. Each set of porcelain cylinders is interconnected with rubber and steel gaskets. Modulus of elasticity and density of porcelain material was taken as $98 \mathrm{GPa}$ and $2627 \mathrm{~kg} / \mathrm{m} 3$. Modulus of elasticity and density of gasket rubber was taken as $0.1 \mathrm{GPA}$ and $1100 \mathrm{~kg} / \mathrm{m} 3$. Modulus of elasticity and density of mild steel was taken as $200 \mathrm{GPa}$ and $7800 \mathrm{~kg} / \mathrm{m} 3$.Multipoint 
constraints were introduced at the nodes of connecting bolts of porcelain elements.

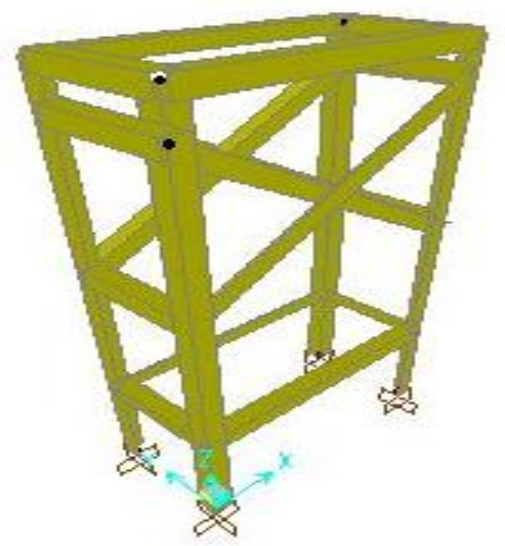

Fig-3: Steel support structure of $36 \mathrm{kV}$ circuit breaker

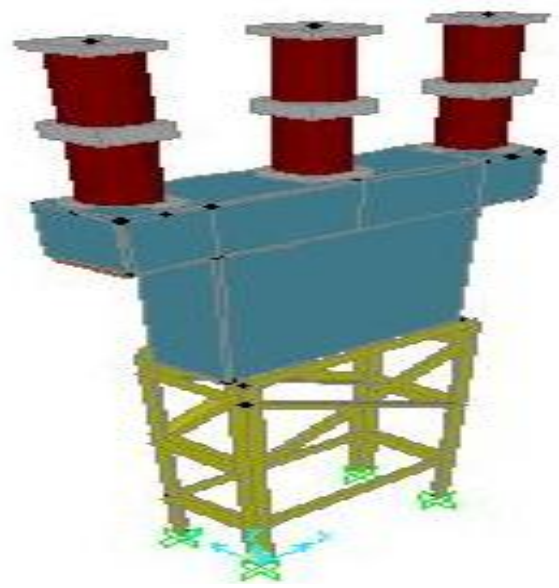

Fig -4: Finite Element model of $36 \mathrm{kV}$ circuit breaker mounted on support structure

Natural frequencies and corresponding mode shapes are determined from modal analysis. The first mode (cantilever mode) of the structure is along $\mathrm{X}$-axis at $6.2 \mathrm{~Hz}$.

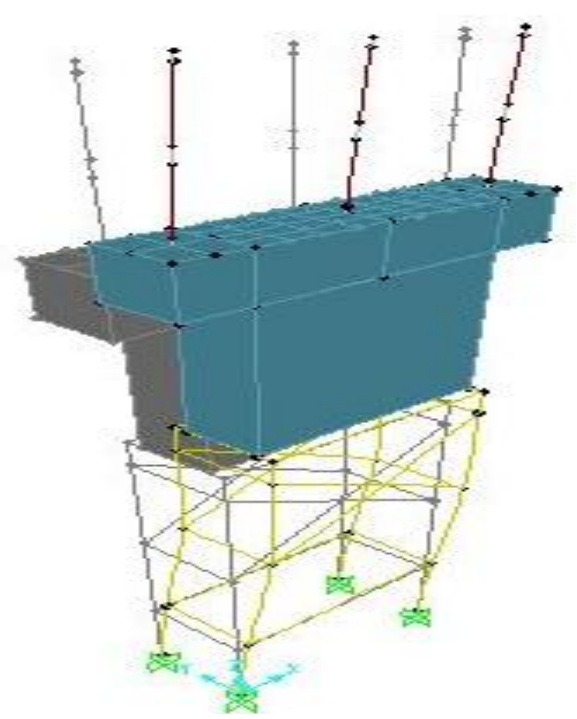

Fig-5: First cantilever mode of $36 \mathrm{kV}$ circuit breaker.
Table 1: Parameters considered for Spectra and Steady state response

\begin{tabular}{|l|l|l|}
\hline 1 & Importance factor & 1.5 \\
\hline 2 & Soil Type & II(Medium Soil) \\
\hline 3 & Response Reduction Factor & 5 \\
\hline 4 & Frequency Range & 1.0 to $60 \mathrm{~Hz}$ \\
\hline 5 & Ground Acceleration & $0.1 \mathrm{~g}$ \\
\hline 6 & Damping & $5 \%$ \\
\hline
\end{tabular}

\section{Response Spectrum Method:}

The scale factor is calculated by using formula $\mathrm{gI} / 2 \mathrm{R}=(9.81 \times 1.5) /(2 \times 5)$ $=1.4715$

For this factor Maximum spectral accelerations and displacements are evaluated with respect to seismic zones IV and V. These results are obtained at the top of the support structure as tabulated below in table 2 .

Table 2: Maximum spectral accelerations and displacements of support structure

\begin{tabular}{|c|c|c|c|c|}
\hline & \multicolumn{2}{|c|}{$\begin{array}{l}\text { Maximum spectral } \\
\text { Accelerations }\left(\mathrm{m} / \mathrm{s}^{2}\right)\end{array}$} & \multicolumn{2}{|c|}{$\begin{array}{l}\text { Maximum spectral } \\
\text { Displacements }(\mathrm{m})\end{array}$} \\
\hline & $\mathrm{X}$-axis & Y-axis & $\mathrm{X}$-axis & Y-axis \\
\hline Zone IV & 0.43 & 0.5 & $2 \mathrm{E}-05$ & $2.6 \mathrm{E}-05$ \\
\hline Zone V & 0.64 & 0.75 & $3 \mathrm{E}-05$ & $3.9 \mathrm{E}-05$ \\
\hline
\end{tabular}

Maximum response spectral accelerations and displacements are obtained from response spectrum analysis of finite element model $36 \mathrm{kv}$ circuit breaker installed on support structure for seismic zone IV and V. These results of the structure are obtained at top of the middle porcelain insulator when the equipment is installed on support structure as in Table 3

Table 3: Maximum spectral accelerations and displacements of $36 \mathrm{kV}$ Circuit Breaker

\begin{tabular}{|c|c|c|c|c|}
\hline & \multicolumn{2}{|c|}{$\begin{array}{l}\text { Maximum spectral } \\
\text { Accelerations }\left(\mathrm{m} / \mathrm{s}^{2}\right)\end{array}$} & \multicolumn{2}{|c|}{$\begin{array}{l}\text { Maximum spectral } \\
\text { Displacements (m) }\end{array}$} \\
\hline & $\mathrm{X}$-axis & $\mathrm{Y}$-axis & $\mathrm{X}$-axis & $\mathrm{Y}$-axis \\
\hline Zone IV & 0.81 & 0.84 & $2.9 \mathrm{E}-04$ & $5.3 \mathrm{E}-04$ \\
\hline Zone V & 1.21 & 1.26 & $4.4 \mathrm{E}-04$ & $7.9 \mathrm{E}-05$ \\
\hline
\end{tabular}

\section{Steady-State Response:}

Frequency response analysis is carried out to identify the resonant frequencies and the corresponding mode shapes. Response of the finite element model for a ground acceleration of $0.1 \mathrm{~g}$ is evaluated using software SAP2000. From the seismic response of the equipment and the structure, ground acceleration amplification at the base of structure termed as amplification factor, i.e., the ratio of acceleration at the base of the porcelain equipment (response) to the ground acceleration (input) at the base of the structure is evaluated from the FE analysis. 


\section{RESULTS}

\subsection{Frequency Response of Support Structure}

The response of the support structure in terms of acceleration at the top of the support structure is obtained. Comparing the input response spectra (ground acceleration) and the excited seismic response of the structure, the amplification factor at different frequencies are evaluated and shown in Fig 6 and Fig 7.

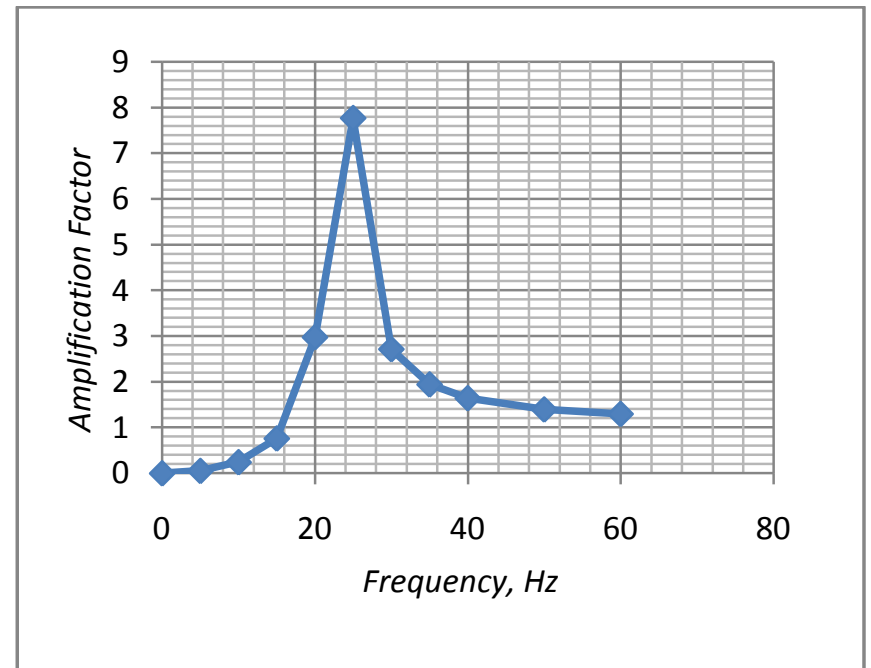

Fig-6: Response Amplification at top of the support structure in $\mathrm{X}$ - Axis

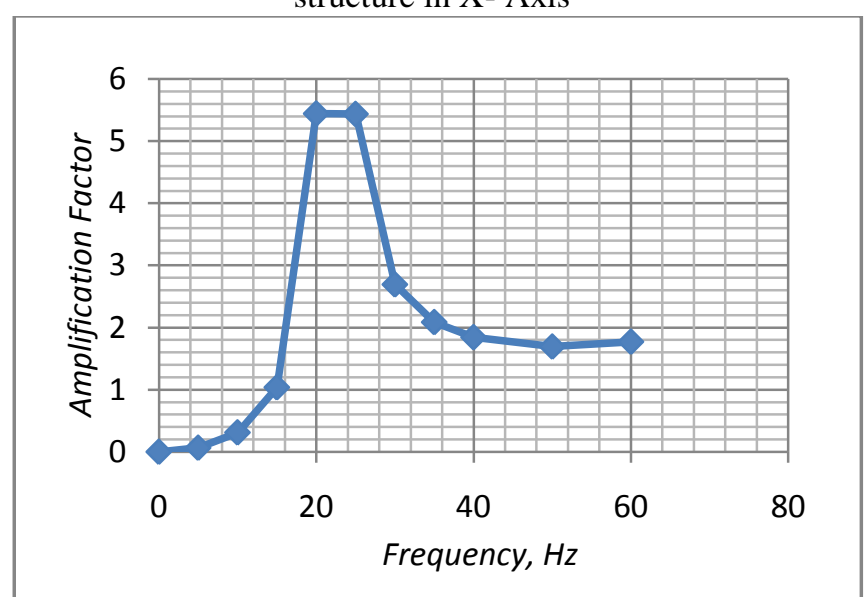

Fig-7: Response Amplification at top of the support structure in Y- Axis

From the finite element results, it can be seen that the acceleration simulated at the base of the supporting structure is amplified nearly 7.6 times at the top of the support structure along transverse $\mathrm{X}$-axis and 5.5 times amplified along Y-axis.

Table 4: Amplification factors and resonant frequencies at top of the support structure

\begin{tabular}{|l|l|l|}
\hline $\begin{array}{l}\text { Acceleration at } \\
\text { top of support } \\
\text { structure }\end{array}$ & $\begin{array}{l}\text { Amplification } \\
\text { w.r.t acceleration }\end{array}$ & $\begin{array}{l}\text { Resonant } \\
\text { frequencies }\end{array}$ \\
\hline X-axis & 7.6 & $25 \mathrm{~Hz}$ \\
\hline Y-axis & 5.5 & $20 \mathrm{~Hz}$ \\
\hline
\end{tabular}

4.2 Frequency Response of $36 \mathrm{kV}$ Circuit Breaker

\section{Placed on Support Structure}

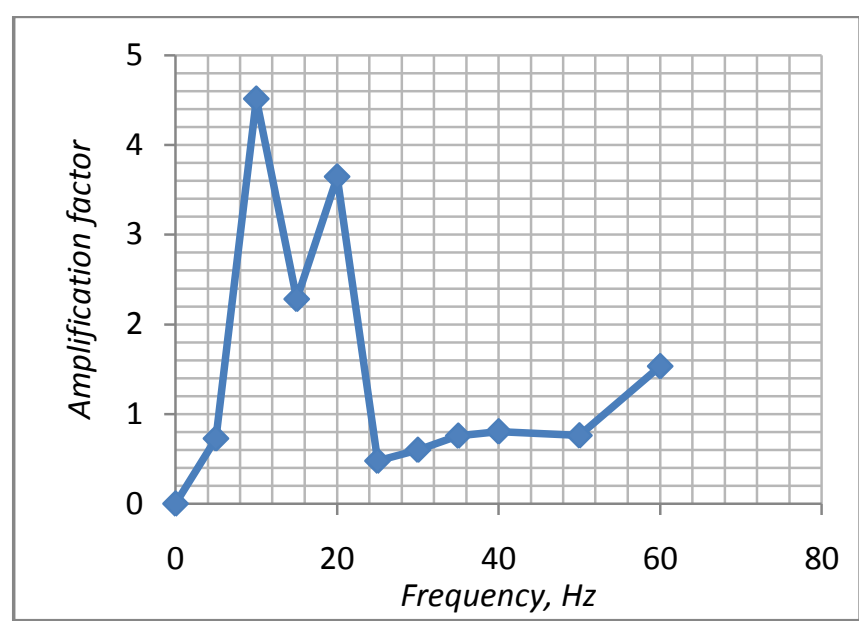

Fig-8: Amplification at top of porcelain insulator $36 \mathrm{kV}$ Circuit Breaker in X-axis

The response of the $36 \mathrm{kV}$ circuit breaker in terms of acceleration at the top of the middle porcelain insulator is obtained. Comparing the input response spectra (ground acceleration) and the excited seismic response of the structure, the amplification factor at different frequencies are evaluated and shown in Fig 8 and Fig 9.

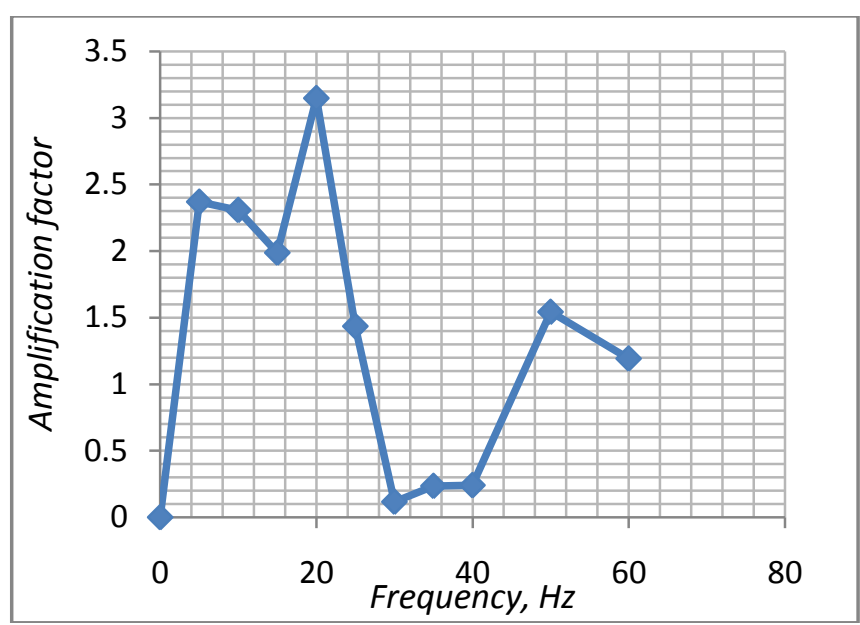

Fig-9: Amplification at top of porcelain insulator of $36 \mathrm{kV}$ Circuit Breaker in Y-axis

Table 5: Amplification Factors and Resonant Frequencies of $36 \mathrm{kv} \mathrm{CB}$ at top middle porcelain insulator

\begin{tabular}{|l|l|l|}
\hline $\begin{array}{l}\text { Acceleration at } \\
\text { top of porcelain } \\
\text { insulator }\end{array}$ & $\begin{array}{l}\text { Amplification } \\
\text { w.r.t acceleration }\end{array}$ & $\begin{array}{l}\text { Resonant } \\
\text { frequencies }\end{array}$ \\
\hline X-axis & 4.5 & $10 \mathrm{~Hz}$ \\
\hline Y-axis & 3.1 & $20 \mathrm{~Hz}$ \\
\hline
\end{tabular}




\subsection{Amplification at Base of Middle Porcelain}

\section{Insulator:}

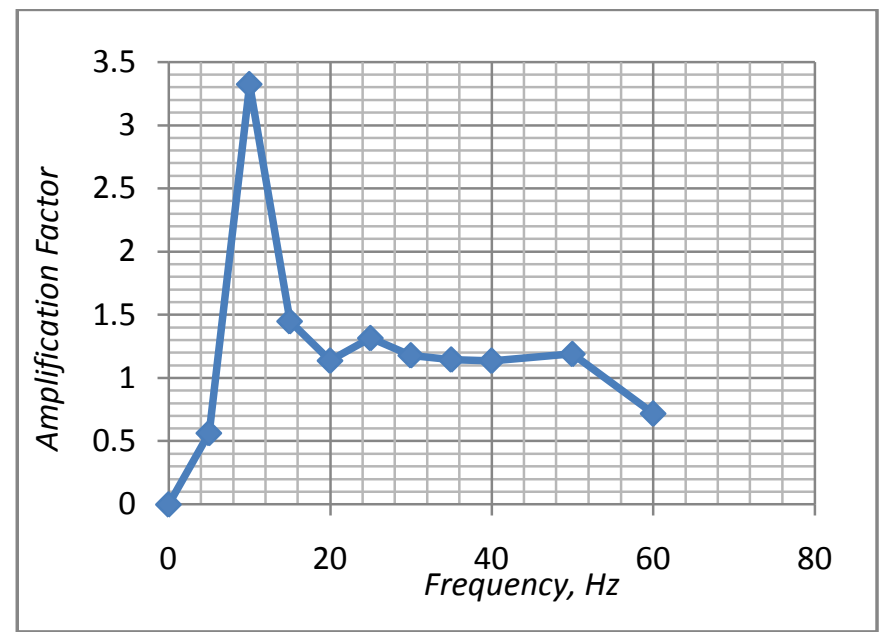

Fig-10: Amplification at base of porcelain insulator of $36 \mathrm{kV}$ Circuit Breaker in $\mathrm{X}$-axis

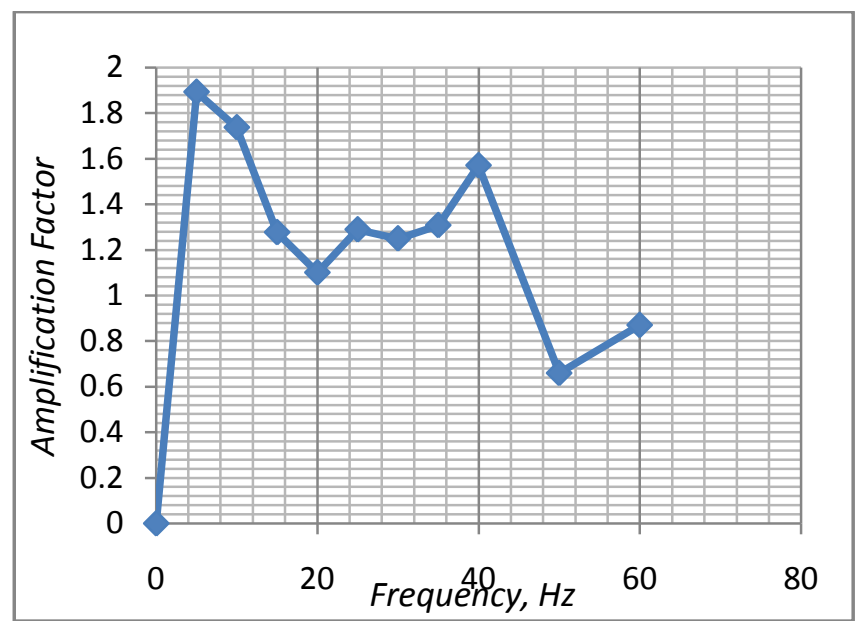

Fig-11: Amplification at base of porcelain insulator of $36 \mathrm{kV}$ Circuit breaker in $\mathrm{Y}$-axis

From the finite element results, it can be seen that the acceleration simulated at the base of the supporting structure is amplified nearly 3.3 times at the top of middle porcelain insulator along transverse $\mathrm{X}$-axis and amplified 1.9 times along $\mathrm{Y}$-axis at the frequencies of $10 \mathrm{~Hz}$ and $5 \mathrm{~Hz}$.

Table 6: Amplification Factors and Resonant Frequencies of $36 \mathrm{kv} \mathrm{CB}$ at top middle porcelain insulator

\begin{tabular}{|l|l|l|}
\hline $\begin{array}{l}\text { Acceleration at } \\
\text { top of support } \\
\text { structure }\end{array}$ & $\begin{array}{l}\text { Amplification } \\
\text { w.r.t } \\
\text { acceleration }\end{array}$ & $\begin{array}{l}\text { Resonant } \\
\text { frequencies }\end{array}$ \\
\hline X-axis & 3.3 & $10 \mathrm{~Hz}$ \\
\hline Y-axis & 1.9 & $5 \mathrm{~Hz}$ \\
\hline
\end{tabular}

\section{CONCLUSIONS}

Finite element analysis is carried out on $36 \mathrm{kV}$ outdoor vacuum circuit breaker for seismic qualification of circuit breaker when it installed on support structure to evaluate the amplification of whole structure to ground amplification and the following conclusions are drawn.

- It has been observed that, the ground motion amplification at the top of support structures is more than the accelerations at the base.

- Though higher amplifications are observed at higher modes, only the first mode in each axis is considered because the mass participation in the first mode i.e., in pure cantilever mode is higher.

- The recommended base acceleration magnitude at lower frequencies is more as it can be seen from the design response spectra stipulated in various standards, the amplification factor corresponding to first mode is critical.

- It is recommended to carry out finite element analysis on a simple analytical model of circuit breaker with suitable assumptions, substation equipment with short porcelain components to evaluate the appropriate amplification factor before conducting seismic qualification tests on isolated porcelain components.

\section{ACKNOWLEDGEMENT}

The authors gratefully acknowledge the encouragement of Shri. R. Ramesh Babu, Additional Director General, CPRI,Bangalore in Bringing out this technical paper.

\section{REFERENCES}

[1]. IEEE Standard 693-2005, IEEE Recommended Practice for Seismic Design of Substations.

[2]. Morteza Bastami, Maryam and Hajihasani (2012), "Proposed Input Waves for Seismic Design of Power Substation Equipments", 15th World Conference on Earthquake Engineering

[3]. Sabelli, R., Mahin, S. and Chang, C. (2003), "Seismic Demands on Steel Braced Frame Buildings with Buckling Restrained Braces", Engineering Structures, Elsevier Journal, Vol-25, pp 655-666.

[4]. Srujana Nandam, Ramesh Babu. R and Katta Venkataramana,(2012) "Full Scale Experiment and Finite Element Modeling of Support Structures of Substation Equipment for Evaluation of Ground Motion Amplification" , International Journal of Earth sciences and Engineering, Volume 05, No. 05 (01), P.P. 1394-1399 